\title{
Article \\ Reliability-Based Design of Driven Piles Considering Setup Effects
}

\author{
Xiaoya Bian ${ }^{1}$, Jiawei Chen ${ }^{1}$, Xuyong Chen ${ }^{1, *}$ and Zhijun $\mathrm{Xu}^{2}$ \\ 1 School of Civil Engineering and Architecture, Wuhan Institute of Technology, Wuhan 430074, China; \\ wit_bianxy@hust.edu.cn (X.B.); chenjw@stu.wit.edu.cn (J.C.) \\ 2 College of Civil Engineering and Architecture, Henan University of Technology, Zhengzhou 450001, China; \\ xuzhijun@haut.edu.cn \\ * Correspondence: chenxy@wit.edu.cn
}

Citation: Bian, X.; Chen, J.; Chen, X.; $\mathrm{Xu}, \mathrm{Z}$. Reliability-Based Design of Driven Piles Considering Setup Effects. Appl. Sci. 2021, 11, 8609 . https://doi.org/10.3390/ app11188609

Academic Editors: Chongchong Qi and Wengang Zhang

Received: 20 August 2021

Accepted: 14 September 2021

Published: 16 September 2021

Publisher's Note: MDPI stays neutra with regard to jurisdictional claims in published maps and institutional affiliations.

Copyright: (c) 2021 by the authors. Licensee MDPI, Basel, Switzerland. This article is an open access article distributed under the terms and conditions of the Creative Commons Attribution (CC BY) license (https:// creativecommons.org/licenses/by/ $4.0 /)$.

\begin{abstract}
The total ultimate resistance (or bearing capacity) of driven piles considering setup effects is composed of initial ultimate resistance and setup resistance, and the setup effects of driven piles are mainly reflected by the setup resistance. In literature, a logarithmic empirical formula is generally used to quantify the setup effects of driven piles. This paper proposes an increase factor $\left(M_{\text {setup }}\right)$ to modify the resistance factor and factor of safety calculation formula in accordance with the load and resistance factor design (LFRD) principle; here, the increase factor is defined as the ratio of the setup resistance $\left(R_{\text {setup }}\right)$ to the initial ultimate resistance $\left(R_{0}\right)$ of driven piles. Meanwhile, the correlation between $R_{0}$ and $R_{\text {setup }}$ is fully considered in the resistance factor and factor of safety calculation. Finally, the influence of four key parameters (ratio of dead load to live load $\rho=Q_{\mathrm{D}} / Q_{\mathrm{L}}$, target reliability index $\beta_{\mathrm{T}}, M_{\text {setup }}$, correlation coefficient between $R_{0}$ and $R_{\text {setup }}, \rho_{\mathrm{R} 0 \text {,Rsetup }}$ ) on the resistance factor and factor of safety are analyzed. Parametric research shows that $\rho$ has basically no effect on the resistance factor, which can be taken as a constant in further research, and $\rho$ has a significant influence on the factor of safety. The value of $M_{\text {setup }}$ has almost no effect on the resistance factor and factor of safety. However, $\beta_{\mathrm{T}}$ and $\rho_{\mathrm{R} 0 \text {,Rsetup }}$ have a significant influence on the resistance factor and factor of safety, so the value selection of $\beta_{\mathrm{T}}$ and $\rho_{\mathrm{R} 0 \text {,Rsetup }}$ are crucial for reliability-based design of driven piles. Through this study, it is concluded that considering setup effects in reliability-based design of driven piles will greatly improve the prediction for design capacity.
\end{abstract}

Keywords: driven piles; reliability-based design; setup effects; load and resistance factor design (LRFD); resistance factor; factor of safety

\section{Introduction}

During the process of pile installation, the excess pore pressure generated dissipates over time, and the effective stress in the soil will increase, which is the main reason for the increase in the total ultimate resistance of driven piles after installation with time [1,2]. This phenomenon is usually called the pile setup. In recent years, the setup effect of piles has been paid more attention. In fact, the total ultimate resistance is composed of initial ultimate resistance and setup resistance, and the setup resistance is the main factor to increase the total ultimate resistance [3-5]. Therefore, determination of setup resistance is important in the reliability-based design of driven piles. Haque et al. [6] report the field results of test piles driven in two different sites in Louisiana to evaluate the setup effect of piles. In order to better understand the effect of soil layering on the setup of piles, $\mathrm{Ng}$ and Ksaibati conducted four medium-scale experiments in the laboratory and concluded that the pile setup trend follows the mode of pore water pressure dissipation in cohesive soil [7]. Haque and Abu-Farsakh [8] analyzed twelve prestressed concrete test piles in different bridge construction projects in Louisiana and established an analysis model to estimate the setup effect of piles. 
Many studies are available in the literature to evaluate the capacity of piles on the basis of static and dynamic load tests. Afsharhasani et al. [9] suggested installing the hydraulic jack as close to the caliche layers as possible. Doan et al. [10] proposed a new CPT method, which can be expected to lead to more reliable estimates of pile capacity. Farhangi et al. [11] presented a method in which the risk of soil liquefaction is reduced by using jet-grouted micropiles in sand. Qubain et al. [12] put forward the importance of understanding the unique aspects of the site geology. Baca and Rybak [13] presented three different pipe pile test methods, which provided the possibility to evaluate the pile base and shaft bearing capacities. However, it is not convenient to evaluate the setup effect of piles.

With the accumulation of experience and understanding of the pile setup phenomenon, some researchers [14-16] recommended that the pile setup phenomenon should be incorporated into the total ultimate resistance by the load and resistance factor design (LRFD) method. LRFD is a more advanced design method than the existing allowable stress design (ASD) [17], and many countries and regions, such as the United States, Canada, China mainland, Japan, Korea, Singapore, Europe, and Hong Kong, have replaced ASD with LRFD.

Against this background, many researchers calculated the resistance factor and factor of safety for driven piles considering the setup effects based on the LRFD method. Komurka et al. [18] used the factor of safety to estimate setup effects in the driven pile resistance. Yang and Liang [19] proposed to incorporate the setup resistance into LRFD of driven piles based on the first-order reliability method (FORM). A framework for calculating the resistance factor of LRFD for driven piles in clay was proposed, which can fully consider all necessary reliability-related parameters [20]. $\mathrm{Ng}$ and Sritharan [21] presented a method to incorporate the economic advantages of a pile setup into LRFD recommendations to further improve the efficiency of bridge foundations. Bian et al. [22] used reliability theory and the LRFD principle to establish an iterative algorithm of estimation of separate resistance factors. According to the LRFD methodology, the development of the analysis model is introduced to estimate the soil setup after the end of driving (EOD), and then the resistance factor of the pile setup is determined [16]. Bian et al. [23] put forward a methodology to separately calculate the resistance factors for ultimate base and shaft resistance for reliability-based design of driven piles considering setup effects based on the LRFD principle.

This paper modifies the resistance factor and factor of the safety formula of driven piles by incorporating setup effects into the LRFD principle. In the modified formula, the increase factor $M_{\text {setup }}=R_{\text {setup }} / R_{0}$, defined as the ratio of setup resistance to initial ultimate resistance, is used to express the increasing degree of the ultimate resistance with time. The influence of parameters (ratio of dead load to live load $\rho=Q_{\mathrm{D}} / Q_{\mathrm{L}}$, target reliability index $\beta_{\mathrm{T}}, M_{\text {setup }}=R_{\text {setup }} / R_{0}$, correlation coefficient between $R_{0}$ and $\left.R_{\text {setup }}, \rho_{\mathrm{R} 0, \mathrm{Rsetup}}\right)$ on the resistance factor and factor of safety are analyzed.

\section{Basic Estimation Methods of Pile Setup}

Due to the pile setup, the total ultimate resistance of driven piles includes two parts, initial ultimate resistance and setup resistance, which can be expressed as the following equation:

$$
R=R_{0}+R_{\text {setup }}
$$

where $R$ is the total ultimate resistance at time $t$ after driving, $R_{0}$ is the initial ultimate resistance at initial time $t_{0}$, and $R_{\text {setup }}$ is the setup resistance at time $t$ after driving.

The significant importance to accurately assess setup resistance for the reliabilitybased design of driven piles is indicated by Equation (1). Therefore, many researchers have paid attention to this issue and proposed empirical relationships for quantifying the setup effects of driven piles. An empirical formula for the setup was presented by Skov and Denver [24] based on a logarithmic augment in pile bearing capacity with time. Long et al. [25] proposed a formula predicting the rate at which the pile capacity augmented with the increase in time. The formula presented by Svinkin et al. [26] was used to predict the setup based on load test data on five concrete piles. An alternative 
method of using a hyperbolic function to predict the setup was developed by Bogard and Matlock [27]. Among the existing formulas, the logarithmic empirical relationship by Skov and Denver [24] has been commonly used for the prediction of the pile setup, that is:

$$
R_{\text {setup }}=R_{0} A \log \frac{t}{t_{0}}
$$

where $t$ is the elapsed time from the end of initial pile driving; $t_{0}$ is the reference time after which the resistance increases become linear on this plot; $A$ is a factor that is a function of soil type and is the rate of pile resistance $\left(R / R_{0}\right)$ increase per log cycle of time $\left(t / t_{0}\right)$.

\section{Estimation of the Resistance Factor of Driven Piles}

\subsection{General LRFD Principle of Driven Piles}

In order to conduct reliability-based design of driven piles, the limit state equation should be established first. If the total ultimate resistance of driven piles $(R)$ and the load effect $(Q)$ are considered, the limit state equation can be expressed as:

$$
g=R-Q=0
$$

Because the LFRD method can well explain the uncertainty in geotechnical engineering, this method is often used for the reliability-based design of driven piles. The basic formula for the limit state design by AASHTO is [28]:

$$
\phi R_{\mathrm{n}} \geq \eta \sum \gamma_{i} Q_{i}
$$

where $\phi$ is the resistance factor; $R_{n}$ is the nominal resistance; $\eta$ is the load modifier to account for effects of ductility, redundancy, and operational importance; $Q_{i}$ is the load effect and $\gamma_{i}$ is the load factor. The value of $\eta$ generally is obtained as 1 .

The load effect $Q$, herein, only includes the combination of the dead load $Q_{\mathrm{D}}$ and the live load $Q_{\mathrm{L}}$, and the LRFD criterion can be expressed as:

$$
\phi R_{n} \geq \gamma_{\mathrm{QD}} Q_{\mathrm{D}}+\gamma_{\mathrm{QL}} Q_{\mathrm{L}}
$$

Therefore, the resistance factor $\phi$ can be estimated as [28]:

$$
\phi=\frac{\lambda_{\mathrm{R}}\left(\gamma_{\mathrm{QD}} \rho+\gamma_{\mathrm{QL}}\right) \times \sqrt{\frac{1+\mathrm{COV}_{\mathrm{QD}}^{2}+\mathrm{COV}_{\mathrm{QL}}^{2}}{1+\mathrm{COV}_{\mathrm{R}}^{2}}}}{\left(\lambda_{\mathrm{QD}} \rho+\lambda_{\mathrm{QL}}\right) \times \exp \left\{\beta_{\mathrm{T}} \sqrt{\ln \left[\left(1+\mathrm{COV}_{\mathrm{R}}^{2}\right)\left(1+\mathrm{COV}_{\mathrm{QD}}^{2}+\mathrm{COV}_{\mathrm{QL}}^{2}\right)\right]}\right\}}
$$

where $\lambda_{\mathrm{R}}, \lambda_{\mathrm{QD}}$, and $\lambda_{\mathrm{QL}}$ are the bias factors for resistance, dead load, and live load, respectively; $\mathrm{COV}_{\mathrm{R}}, \mathrm{COV}_{\mathrm{QD}}$, and $\mathrm{COV}_{\mathrm{QL}}$ are the coefficients of variation (COVs) for resistance, dead load, and live load, respectively. The following relevant statistics for $Q_{D}$ and $Q_{\mathrm{L}}$ are accepted for further study: $\lambda_{\mathrm{QD}}=1.080, \lambda_{\mathrm{QL}}=1.150, \sigma_{\mathrm{QD}}=0.140, \sigma_{\mathrm{QL}}=0.207$, $\mathrm{COV}_{\mathrm{QD}}=0.130$, and $\mathrm{COV}_{\mathrm{QL}}=0.180$ [28]. Meanwhile, the distributions of $Q_{\mathrm{D}}$ and $Q_{\mathrm{L}}$ are assumed to be lognormal.

The corresponding factor of safety (FOS) in allowable stress design (ASD) can be calculated as follows:

$$
F O S=\frac{\gamma_{Q D} \rho+\gamma_{Q L}}{\phi(1+\rho)}
$$


Substituting Equation (6) for (7), the computed formulas for the factor of safety for driven piles are as follows:

$$
F O S=\frac{\left(\lambda_{\mathrm{QD}} \rho+\lambda_{\mathrm{QL}}\right) \times \exp \left\{\beta_{\mathrm{T}} \sqrt{\ln \left[\left(1+\mathrm{COV}_{\mathrm{R}}^{2}\right)\left(1+\mathrm{COV}_{\mathrm{QD}}^{2}+\mathrm{COV}_{\mathrm{QL}}^{2}\right)\right]}\right\}}{\lambda_{\mathrm{R}}(1+\rho) \times \sqrt{\frac{1+\mathrm{COV}_{\mathrm{QD}}^{2}+\mathrm{COV}_{\mathrm{QL}}^{2}}{1+\mathrm{COV}_{\mathrm{R}}^{2}}}}
$$

\subsection{Considering Setup Effects in the LRFD Principle of Driven Piles}

In order to make the reliability-based design of driven piles conform to the LRFD framework, the principle of strength limit state function corresponding to setup effects is expanded as:

$$
g=R_{0}+R_{\text {setup }}-Q_{\mathrm{D}}-Q_{\mathrm{L}}=0
$$

As the ultimate resistance of driven piles increases over time after pile driving, the setup effects further affect the resistance of driven piles. Incorporating the setup effect in the LRFD principle of driven piles is remarkable progress. For this, the LRFD standard can be re-expressed as:

$$
\phi\left(R_{0}+R_{\text {setup }}\right) \geq \gamma_{\mathrm{QD}} Q_{\mathrm{D}}+\gamma_{\mathrm{QL}} Q_{\mathrm{L}}
$$

The ratio of the setup resistance to the initial ultimate resistance of the driven piles is called the increase factor of the ultimate resistance of driven piles and denoted as $M_{\text {setup }}$ by Equation (11).

$$
M_{\text {setup }}=\frac{R_{\text {setup }}}{R_{0}}
$$

Based on Equations (2) and (11), the increase factor $M_{\text {setup }}$ is re-expressed by:

$$
M_{\text {setup }}=A \log \frac{t}{t_{0}}
$$

It can be seen from Equation (12) that $M_{\text {setup }}$ is mainly determined by parameters $A$ and $\log \left(t / t_{0}\right)$. The research in Yang and Liang [19] indicated the approximate range of $A$ from 0.1 to 1 for driven piles in clay. Meanwhile, Yang and Liang [29] also defined the approximate range of $A$ from 0.1 to 0.9 for driven piles in sand. Comparing the results about parameter $A$ from Yang and Liang $[19,29]$, it is reasonable to accept the values of $A$ from 0.1 to 1 in this study. Furthermore, time $t$ after EOD for most cases occurs between 1 day and 100 days, for which $\log \left(t / t_{0}\right)$ with $t_{0}=1$ is between 0 and 2 . Therefore, compiling the analysis about parameters $A$ and $\log \left(t / t_{0}\right)$, the increase factor $M_{\text {setup }}$ is determined in the range of 0 to 2 for this study.

Then, Equations (13) and (14) are obtained based on Equation (11) and the LRFD principle [28]:

$$
\lambda_{\mathrm{R}} R_{\mathrm{n}}=\lambda_{\mathrm{R} 0} R_{0}+\lambda_{\text {Rsetup }} R_{\text {setup }}=\left(\lambda_{\mathrm{R} 0}+\lambda_{\text {Rsetup }} M_{\text {setup }}\right) R_{0}
$$

and

$$
\lambda_{\mathrm{R}} R_{\mathrm{n}}=\lambda_{\mathrm{R}}\left(R_{0}+R_{\text {setup }}\right)=\lambda_{\mathrm{R}}\left(1+M_{\text {setup }}\right) R_{0}
$$

so

$$
\lambda_{\mathrm{R}}=\frac{\lambda_{\mathrm{R} 0}+\lambda_{\mathrm{Rsetup}} M_{\text {setup }}}{1+M_{\text {setup }}}
$$

where $\lambda_{\mathrm{R} 0}$ is the bias factors for pile resistance at initial time $t_{0}$.

Substituting Equation (15) into (6), the computed formulas for the resistance factor of driven piles considering setup effects is as follows: 


$$
\phi=\frac{\frac{\lambda_{\mathrm{R} 0}+\lambda_{\text {Rsetup }} M_{\text {setup }}}{1+M_{\text {setup }}} \times\left(\gamma_{\mathrm{QD}} \rho+\gamma_{\mathrm{QL}}\right) \times \sqrt{\frac{1+\mathrm{COV}_{\mathrm{QD}}^{2}+\mathrm{COV}_{\mathrm{QL}}^{2}}{1+\mathrm{COV}_{\mathrm{R} 0}^{2}+\mathrm{COV}_{\text {Rsetup }}^{2}}}}{\left(\lambda_{\mathrm{QD}} \rho+\lambda_{\mathrm{QL}}\right) \times \exp \left\{\beta_{\mathrm{T}} \sqrt{\ln \left[\left(1+\mathrm{COV}_{\mathrm{R} 0}^{2}+\mathrm{COV}_{\text {Rsetup }}^{2}\right)\left(1+\mathrm{COV}_{\mathrm{QD}}^{2}+\mathrm{COV}_{\mathrm{QL}}^{2}\right)\right]}\right\}}
$$

In Equation (16), the formation mechanisms of initial ultimate resistance and setup resistance indicate that the development of the total ultimate resistance of driven piles is the result of the synergistic effect of initial ultimate resistance and setup resistance. Therefore, with the interaction between the initial ultimate resistance and setup resistance of driven piles, the inevitable correlation that exists between $R_{0}$ and $R_{\text {setup }}$ should be seriously considered in reliability-based design. The expressions of the resistance factor of driven piles, considering the correlation between $R_{0}$ and $R_{\text {setup }}$, is:

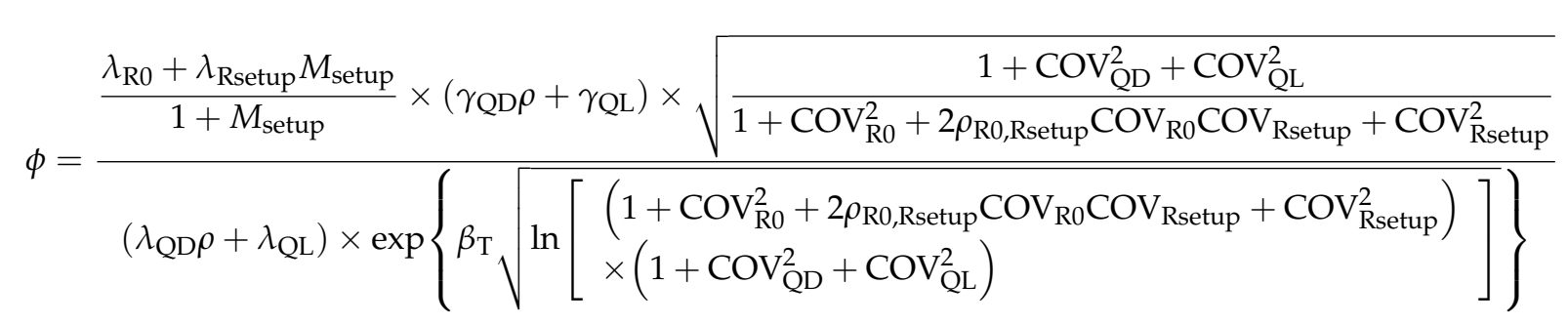

where $\rho_{\mathrm{R} 0, \mathrm{Rsetup}}$ is the correlation coefficient between $R_{0}$ and $R_{\text {setup }}$. When the distributions of $R_{0}$ and $R_{\text {setup }}$ are assumed to be lognormal, the following relevant statistics for $R_{0}$ and $R_{\text {setup }}$ are accepted for further study: $\lambda_{\mathrm{R} 0}=1.158, \lambda_{\text {Rsetup }}=1.023, \sigma_{\mathrm{R} 0}=0.393, \sigma_{\text {Rsetup }}=0.593$, $\mathrm{COV}_{\mathrm{R} 0}=0.339$, and $\mathrm{COV}_{\text {Rsetup }}=0.580$, by referring to these literatures $[29,30]$. Meanwhile, when the distributions of $R_{\text {setup }}$ are assumed to be normal, the following relevant statistics for $R_{\text {setup }}$ are accepted for further study: $\lambda_{\text {Rsetup }}=1.141, \sigma_{\text {Rsetup }}=0.543$ and $\mathrm{COV}_{\text {Rsetup }}=0.475[19]$.

Substituting Equation (15) into (8), the computed formulas for the factor of safety of driven piles considering setup effects is as follows:

$$
F O S=\frac{\left(\lambda_{\mathrm{QD}} \rho+\lambda_{\mathrm{QL}}\right) \times \exp \left\{\beta_{\mathrm{T}} \sqrt{\ln \left[\left(1+\mathrm{COV}_{\mathrm{R} 0}^{2}+\mathrm{COV}_{\mathrm{R} \text { setup }}^{2}\right) \times\left(1+\mathrm{COV}_{\mathrm{QD}}^{2}+\mathrm{COV}_{\mathrm{QL}}^{2}\right)\right]}\right\}}{\frac{\lambda_{\mathrm{R} 0}+\lambda_{\text {Rsetup }} M_{\text {setup }}}{1+M_{\text {setup }}} \times(1+\rho) \times \sqrt{\frac{1+\mathrm{COV}_{\mathrm{QD}}^{2}+\mathrm{COV}_{\mathrm{QL}}^{2}}{1+\mathrm{COV}_{\mathrm{R} 0}^{2}+\mathrm{COV}_{\mathrm{R} \text { setup }}^{2}}}}
$$

Therefore, the expressions of the factor of safety of driven piles, considering the correlation between $R_{0}$ and $R_{\text {setup }}$, is:

$$
F O S=\frac{\left(\lambda_{\mathrm{QD}} \rho+\lambda_{\mathrm{QL}}\right) \times \exp \left\{\beta_{\mathrm{T}} \sqrt{\ln \left[\begin{array}{l}
\left(1+\mathrm{COV}_{\mathrm{R} 0}^{2}+2 \rho_{\mathrm{R} 0, \mathrm{Rsetup}} \mathrm{COV}_{\mathrm{R} 0} \mathrm{COV}_{\text {Rsetup }}+\mathrm{COV}_{\mathrm{Rsetup}}^{2}\right) \\
\times\left(1+\mathrm{COV}_{\mathrm{QD}}^{2}+\mathrm{COV}_{\mathrm{QL}}^{2}\right)
\end{array}\right)}\right.}{\frac{\lambda_{\mathrm{R} 0}+\lambda_{\mathrm{Rsetup}} M_{\text {setup }}}{1+M_{\text {setup }}} \times(1+\rho) \times \sqrt{\frac{1+\mathrm{COV}_{\mathrm{QD}}^{2}+\mathrm{COV}_{\mathrm{QL}}^{2}}{1+\mathrm{COV}_{\mathrm{R} 0}^{2}+2 \rho_{\mathrm{R} 0, \text { Rsetup }} \mathrm{COV}_{\mathrm{R} 0} \mathrm{COV}_{\text {Rsetup }}+\mathrm{COV}_{\text {Rsetup }}^{2}}}}
$$

\section{Parametric Analysis}

\subsection{Effect of $\rho$ on the Resistance Factor and the Factor of Safety}

This section intends to study the effect of $\rho$ on the resistance factor and the factor of safety for driven piles. $\beta_{\mathrm{T}}$ is designed as 2.33 (corresponding failure probability is 0.01 ), 
and the increase factor $M_{\text {setup }}$ is accepted as a value of 1 , which is the mean value of the recommended range between 0 and 2. According to Hansell et al. [31] point out that for the relationship of the ratio of $\rho=Q_{\mathrm{D}} / Q_{\mathrm{L}}$ and the bridge span length, the values in the range of 0.5 to 4 for $\rho=Q_{\mathrm{D}} / Q_{\mathrm{L}}$ are used. It should be noted that the correlation between $R_{0}$ and $R_{\text {setup }}$ is not considered in this section. Based on these proposed values of key parameters, the resistance factor and factor of safety can be calculated using Equations (17) and (19). The variations of the calculated resistance factor and factor of safety with $\rho=Q_{\mathrm{D}} / Q_{\mathrm{L}}$ for driven piles in clay and sand are shown in Figure 1.
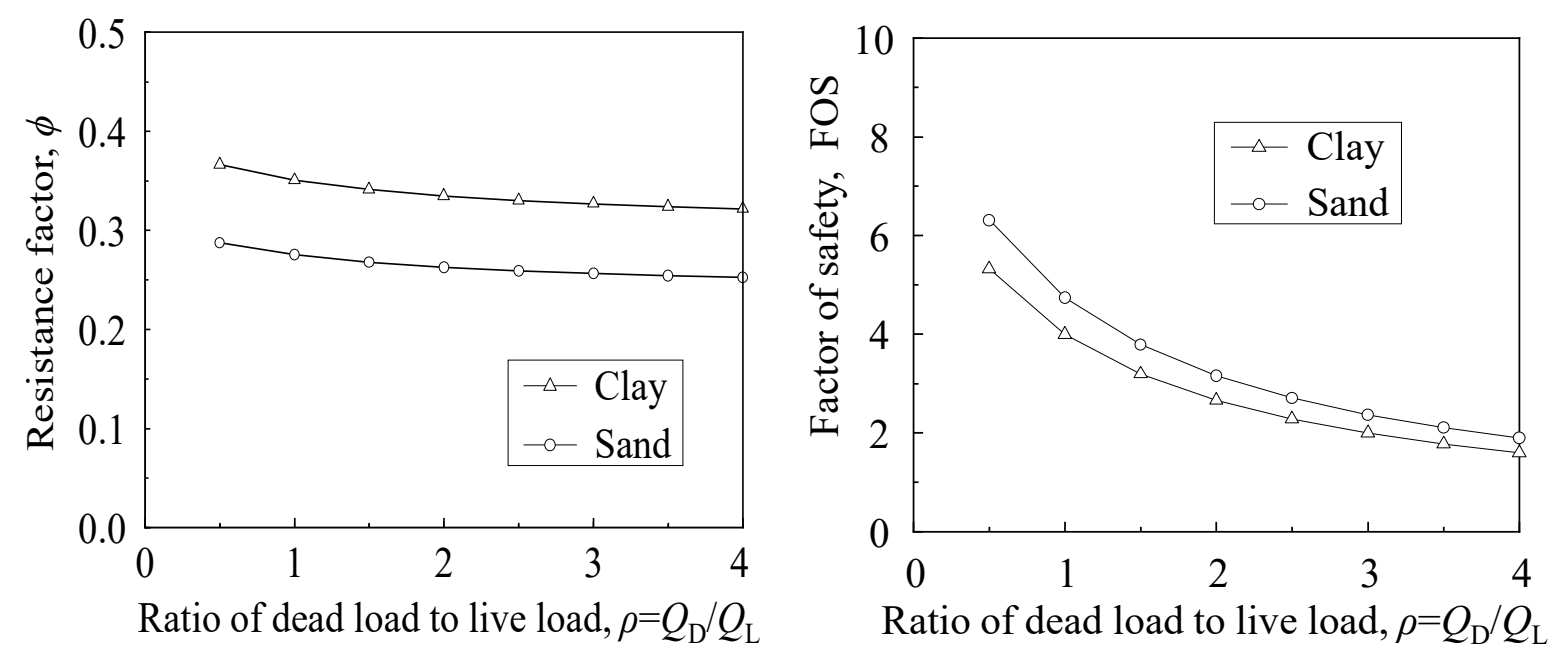

Figure 1. Resistance factor and factor of safety with $\rho$ for driven piles in clay and sand.

$\phi$ slightly decreases as $\rho$ increases from 0.5 to 4 in the distribution curve of $\phi$ versus $\rho$. In particular, the resistance factor decreases obviously when $\rho$ is between 0.5 and 2 , but the resistance factor tends to be constant when $\rho$ is between 2 and 4 . Meanwhile, Figure 1 also can verify driven piles considering setup effects have greater uncertainties in sand, because the resistance factor of driven piles in clay is larger than the resistance factor of driven piles in sand for the same value of $\rho$, the average difference is about 22\%. Particularly, for $\rho=2.0$, the recommended resistance factor of driven piles in clay and sand are estimated as 0.26 and 0.20 , respectively.

The value of FOS decreases obviously as $\rho$ increases from 0 to 4 in the distribution curve of FOS versus $\rho$, but the decreasing rate decreases gradually, and the value of FOS approaches a constant when $\rho$ tends to infinity. Meanwhile, when $\rho$ increases from 0 to 4 , the value of FOS nearly decreases from 7.98 to 1.6 in clay, with a decrement of about $79.9 \%$; when $\rho$ increases from 0 to 4 , the value of FOS nearly decreases from 9.47 to 1.89 in sand, with a decrement of about $80 \%$. Therefore, the value of $\rho$ is one of the most important factors for the factor of safety.

By comparing the two figures in Figure 1, it can be concluded that the resistance factor and factor of safety for driven piles in sand and clay both decrease with the increase in $\rho$, but varying $\rho$ is not largely sensitive to the resistance factor for reliability-based design of driven piles, which is consistent with other research in this field [32,33]. On the contrary, the factor of safety for driven piles in clay and sand decreases greatly with $\rho$.

\subsection{Effect of $\beta_{T}$ on the Resistance Factor and the Factor of Safety}

$\beta_{\mathrm{T}}$ is one of the most important factors for reliability-based design of driven piles. The six allowable values of $\beta_{\mathrm{T}}$ are $1.5,2.0,2.5,3.0,3.5$, and 4.0, respectively, and it is indisputably accepted to study the effect of $\beta_{\mathrm{T}}$ on the resistance factor and the factor of safety for driven piles. Meanwhile, some parameters are determined as follows, $M_{\text {setup }}=1.0, \rho=3.69[34,35]$. It should be noted that the correlation between $R_{0}$ and $R_{\text {setup }}$ is not considered in this section. Using the above parameters, the resistance factor and the factor of safety are 
calculated by Equations (17) and (19), and the relationships between the resistance factor and the factor of safety against $\beta_{\mathrm{T}}$ are shown in Figure 2.
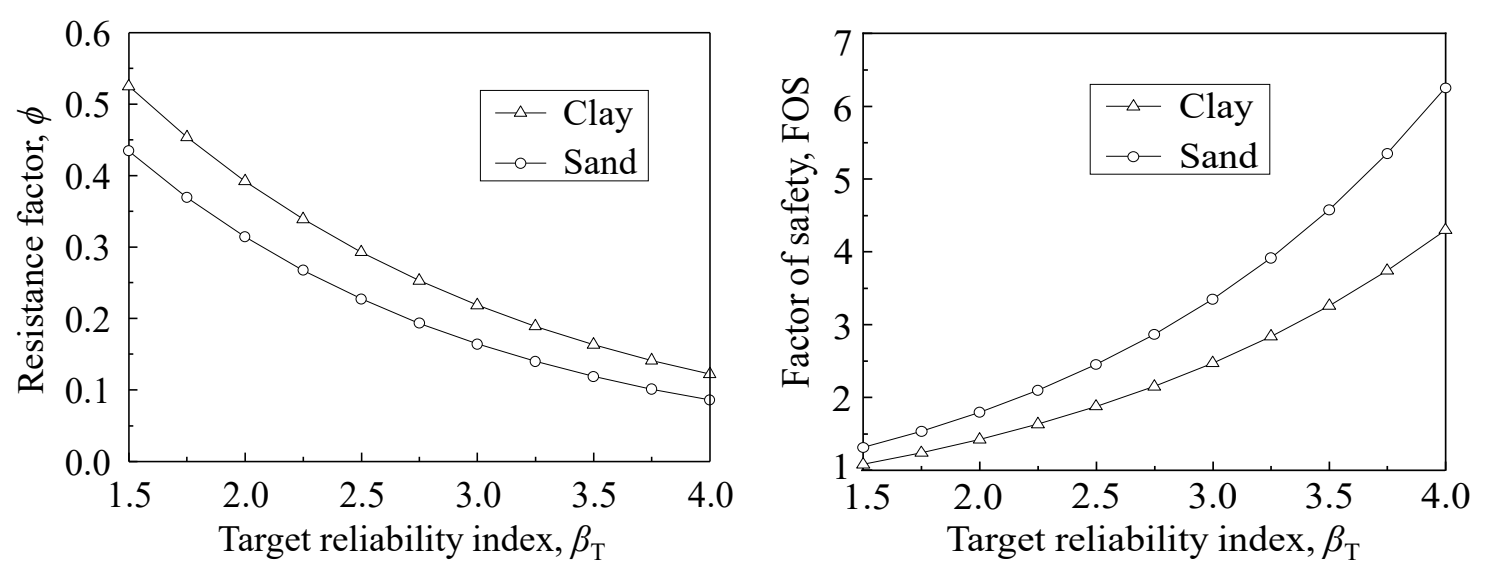

Figure 2. Resistance factor and factor of safety with $\beta_{\mathrm{T}}$ for driven piles in clay and sand.

In the distribution curve of $\phi$ versus $\beta_{\mathrm{T}}$, it is obvious that the $\phi$ of driven piles in clay and sand both decrease with the increase in $\beta_{\mathrm{T}}$. The $\phi$ of driven piles decreases tardily with $\beta_{\mathrm{T}}$ increasing from 1.5 and 2.5 , and by contrast, decreases rapidly with increasing $\beta_{\mathrm{T}}$ from 2 to 4 . These phenomena illustrate that $\phi$ of driven piles in clay and sand are sensitive to $\beta_{\mathrm{T}}$. When $\beta_{\mathrm{T}}$ increases from 1.5 to $4.0, \phi$ nearly decreases from 0.52 to 0.12 in clay, with a decrement of about $77 \%$; when $\beta_{\mathrm{T}}$ increases from 1.5 to $4, \phi$ nearly decreases from 0.43 to 0.09 in sand, with a decrement of about $79 \%$.

In the distribution curve of FOS versus $\beta_{T}$, it is obvious that the value of the FOS of driven piles in clay and sand both increase with the increase in $\beta_{\mathrm{T}}$, and the FOS of driven piles decreases rapidly with increasing $\beta_{\mathrm{T}}$ from 2.5 to 4 . These phenomena indicate that the higher the target reliability of driven piles is, the safer the structure is.

By comparing the two figures in Figure 2, it can be concluded that $\beta_{\mathrm{T}}$ has a significant effect on the resistance factor and factor of safety. Therefore, the value of $\beta_{\mathrm{T}}$ is one of the most important factors for the reliability-based design of driven piles.

\subsection{Effect of $M_{\text {setup }}$ on the Resistance Factor and the Factor of Safety}

$M_{\text {setup }}$ is one of the important factors for analyzing the influence of the resistance factor and the factor of safety. Therefore, in order to study the influence of $M_{\text {setup }}$ on the resistance factor and factor of safety for driven piles in clay and sand, the values of key parameters are determined, such as $\beta_{\mathrm{T}}=2.33$ and $\rho=3.69$. It should be noted that the correlation between $R_{0}$ and $R_{\text {setup }}$ is not considered in this section. Meanwhile, based on the previous discussion of $M_{\text {setup }}$, there are sufficient reasons to make $M_{\text {setup }}$ equal to 0.5, $1.0,1.5,2.0,2.5,3.0,3.5$ and 4.0 , respectively. The varying regularity of the resistance factor and factor of safety for the driven piles in clay and sand with $M_{\text {setup }}$ are shown in Figure 3.

In the distribution curve of $\phi$ versus $M_{\text {setup, }}$ it can be obviously seen that the $\phi$ of driven piles in sand decreases slowly with the increase in $M_{\text {setup. In the clay, the resistance factor }}$ of the driven piles remains basically unchanged with the increase in $M_{\text {setup. }}$. Meanwhile, it can be seen from Equations (11) and (12) that the value of $M_{\text {setup }}$ is larger and the value of $R_{\text {setup }}$ is larger. The value of $M_{\text {setup }}$ is determined by the type of soil, so it is concluded that the size of $M_{\text {setup }}$ is adjusted by selecting different soil, and then the size of $R_{\text {setup }}$ is controlled. 

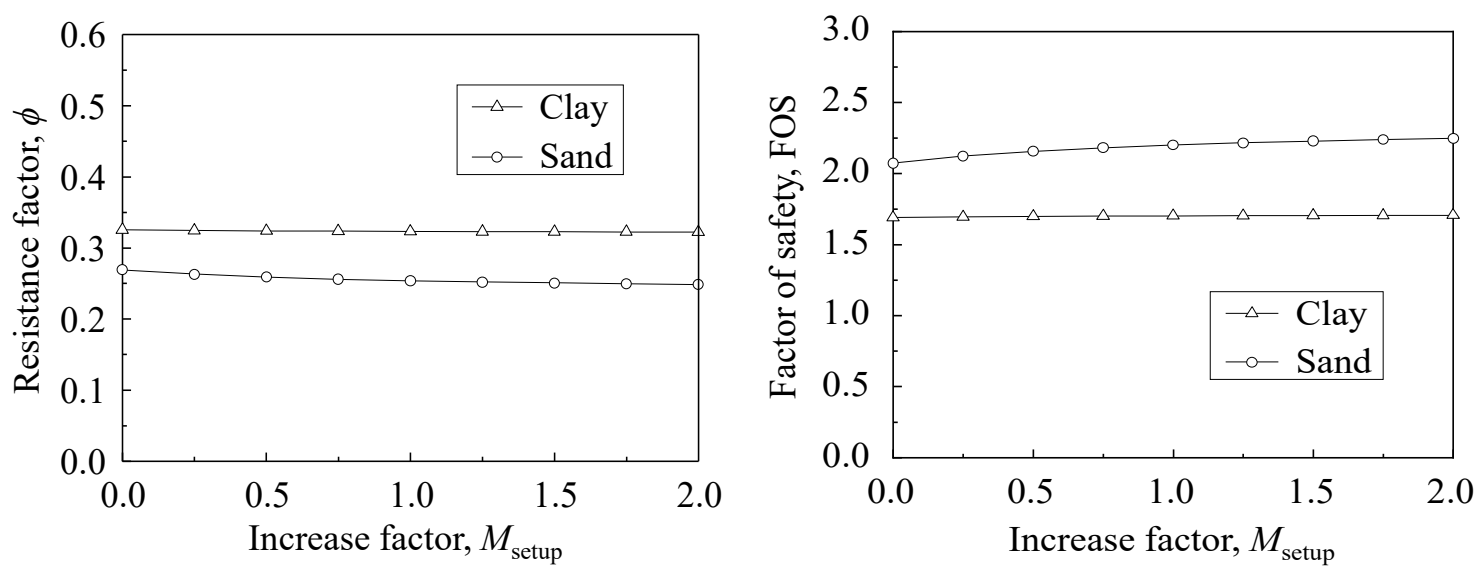

Figure 3. Resistance factor and factor of safety with $M_{\text {setup }}$ for driven piles in clay and sand.

In the distribution curve of FOS versus $M_{\text {setup }}$, it can be obviously seen that the value of FOS of driven piles in sand and clay both increase slowly with the increase in $M_{\text {setup }}$. It can be further seen that the calculated factor of safety of driven piles in sand is larger than those in clay, and the difference between them is about $20 \%$ for a given $M_{\text {setup. This }}$ phenomenon shows that the type of soil has a great influence on the factor of safety for driven piles, which should be emphasized in practical application.

By comparing the two figures in Figure 3, it can be concluded that the resistance factor of driven piles in sand and clay decreases with the increase in $M_{\text {setup, }}$ while the factor of safety for driven piles in clay and sand increases with the increase in $M_{\text {setup }}$. Particularly, no matter how $M_{\text {setup }}$ changes, the resistance factor and the factor of safety remain basically unchanged. Therefore, the final resistance factor of driven piles in clay and sand are 0.25 and 0.19 , respectively, and the final factor of safety of driven piles in clay and sand are 1.70 and 2.20 , respectively.

\subsection{Effect of $\rho_{\mathrm{R} 0 \text {,Rsetup }}$ on Resistance Factor and Factor of Safety}

In order to illustrate the effect of the correlation coefficient between $R_{0}$ and $R_{\text {setup, }}$, $\rho_{\mathrm{R} 0, \text { Rsetup }}$ on resistance factor and factor of safety for driven piles in sand and clay, Equations (16) and (18) are used to calculate the resistance factor and factor of safety. Meanwhile, in order to further analyze the influence of $\rho_{\mathrm{R} 0, \mathrm{Rsetup}}$ on the resistance factor and the factor of safety, some parameters are determined, for example $\beta_{\mathrm{T}}=2.33, M_{\text {setup }}=1.0$, $\rho=3.69$. The variations of the calculated resistance factor and factor of safety with $\rho_{\text {Ro, Rsetup }}$ for driven piles in clay and sand are shown in Figure 4.

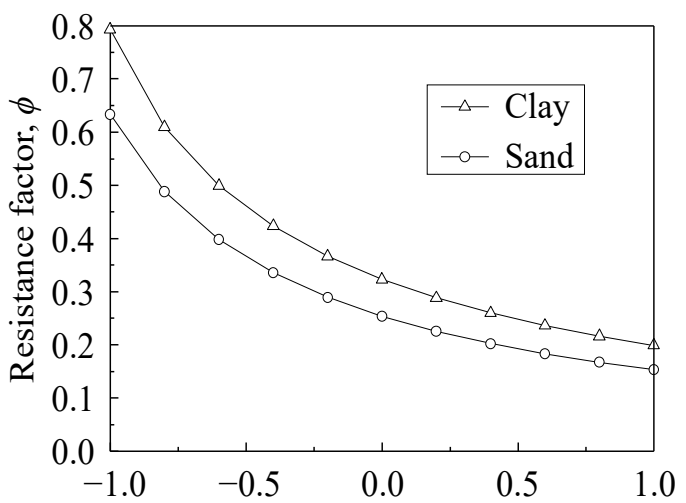

Correlation coefficient between $R_{0}$ and $R_{\text {setup }}, \rho_{\mathrm{R}_{0}, \mathrm{R}_{\text {setup }}}$

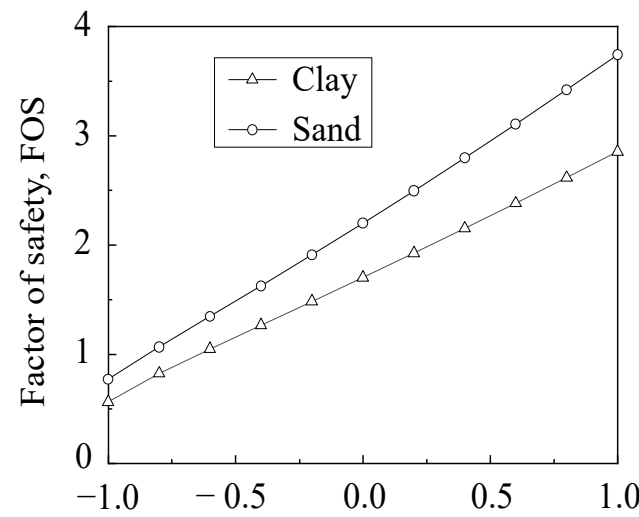

Correlation coefficient between $R_{0}$ and $R_{\text {setup }}, \rho_{\mathrm{R}_{0}, \mathrm{R}_{\text {setup }}}$

Figure 4. Resistance factor and factor of safety with $\rho_{\mathrm{R} 0, \text { Rsetup }}$ for driven piles in clay and sand. 
It can be seen that the resistance factor of driven piles in clay and sand both decrease with increasing $\rho_{\mathrm{R} 0, \mathrm{Rsetup}}$, but the decreasing rate of resistance factor with $\rho_{\mathrm{R} 0, \mathrm{Rsetup}}$ between

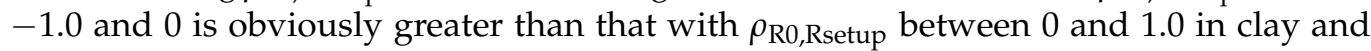
sand. This indicates that the negative correlation between $R_{0}$ and $R_{\text {setup }}$ has a significant influence on the resistance factor of driven piles, while the positive correlation between $R_{0}$ and $R_{\text {setup }}$ has a slight influence on the resistance factor of driven piles. It is obvious from Figure 4 that the resistance factor of driven piles in clay and the resistance factor of driven piles in sandy are quite different, and the difference is about $20 \%$ under the

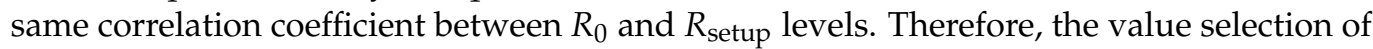
$\rho_{\mathrm{R} 0 \text {,Rsetup }}$ is crucial in geotechnical engineering.

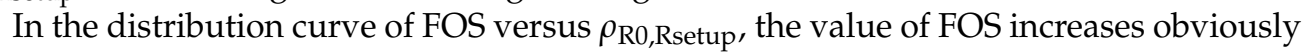
when $\rho_{\text {R0,Rsetup }}$ increases from -1 to 1 . The increasing rate of driven piles in sand increases gradually, but the decreasing rate of driven piles in clay decreases gradually. This indicates that the positive correlation between $R_{0}$ and $R_{\text {setup }}$ has a significant influence on the safety of driven piles, while the negative correlation between $R_{0}$ and $R_{\text {setup }}$ has a little influence on the safety of driven piles.

\section{Conclusions}

There are the following conclusions to be obtained.

(1) $\rho=Q_{\mathrm{D}} / Q_{\mathrm{L}}$ has basically no effect on the resistance factor of driven piles in clay and sand, so $\rho$ can be regarded as a constant. Meanwhile, the resistance factor of driven piles in clay is greater than the resistance factor of driven piles in sand under the same ratio of dead load to live load level. It shows that the uncertainty of driven piles considering setup effects in sand is greater than the uncertainty of driven piles considering setup effects in clay.

(2) Through the analysis of parametric $\beta_{\mathrm{T}}$, it is found that the smaller the resistance of the driven piles is, the higher the factor of safety for the driven piles, and the more reliable the driven piles are.

(3) Through the analysis of parametric $M_{\text {setup }}$, it is found that the soil type has a great influence on the reliability-based design of driven piles. Meanwhile, whichever value of $M_{\text {setup }}$ is selected, the resistance factor of driven piles considering setup effects in sand and clay are basically 0.25 and 0.32 , respectively, and the factor of safety for driven piles considering setup effects in clay and sand are basically 1.7 and 2.2, respectively.

(4) The analysis of the influence of $\rho_{\mathrm{R} 0 \text {,Rsetup }}$ on the resistance factor and factor of safety for driven piles indicates that the negative correlation between $R_{0}$ and $R_{\text {setup }}$ has a significant influence on the resistance factor of driven piles, while the positive correlation between $R_{0}$ and $R_{\text {setup }}$ has a slight influence on the resistance factor of driven piles. However, the factor of safety is just the opposite. Therefore, the correlation between $R_{0}$ and $R_{\text {setup }}$ should be paid attention to in engineering applications.

This paper proposes a methodology to calculate the resistance factor and factor of safety for driven piles considering the setup effects. Through parametric analysis, it is concluded that the total ultimate resistance is significantly improved when driven piles consider the setup effects. The length of the pile or the number of piles could be reduced, and an economic design of driven piles could be achieved.

Author Contributions: Conceptualization, X.B.; methodology, X.B., X.C.; validation, X.B., X.C., J.C. and Z.X.; writing-original draft preparation, X.B. and J.C.; writing-review and editing, X.B., J.C. and Z.X. All authors have read and agreed to the published version of the manuscript.

Funding: This work was supported by the National Natural Science Foundation of China (52078396, 51978247, 51708428).

Conflicts of Interest: The authors declare no conflict of interest. 


\section{References}

1. Konrad, J.M.; Roy, M. Bearing capacity of friction piles in marine clay. Geotechnique 1987, 37, 163-175. [CrossRef]

2. Carter, J.P.; Randolph, M.F.; Wroth, C.P. Stress and pore pressure changes in clay during and after the expansion of a cylindrical cavity. Numer. Anal. Methods Geomech. 1980, 17, 305-322. [CrossRef]

3. Chow, F.C.; Jardine, R.J.; Brucy, F.; Nauroy, J.F. Effects of time on capacity of pipe piles in dense marine sand. J. Geotech. Geoenvironmental Eng. 1999, 125, 254-264.

4. Fellenius, B.H.; Riker, R.E.; O’Brien, A.J.; Tracy, G.R. Dynamic and static testing in soil exhibiting set-up. J. Geotech. Eng. 1989, 115, 984-1001. [CrossRef]

5. Bullock, P.J.; Schmertmann, J.H.; McVay, M.C.; Townsend, F.C. Side shear set-up. I: Test piles driven in florida. J. Geotech. Geoenvironmental Eng. 2005, 131, 292-300. [CrossRef]

6. Haque, M.N.; Abu-Farsakh, M.Y.; Zhang, Z.J. Evaluation of pile capacity from CPT and pile setup phenomenon. Int. J. Geotech. Eng. 2020, 14, 196-205. [CrossRef]

7. $\mathrm{Ng}, \mathrm{K} . ;$ Ksaibati, R. Effect of soil layering on shorter-term pile setup. J. Geotech. Geoenvironmental Eng. 2018, 144, 04018020. [CrossRef]

8. Haque, M.N.; Abu-Farsakh, M.Y. Development of analytical models to estimate the increase in pile capacity with time (pile setup) from soil properties. Acta Geotech. 2019, 14, 881-905. [CrossRef]

9. Afsharhasani, R.; Karakouzian, M.; Farhangi, V. Effect of competent caliche layers on measuring the capacity of axially loaded drilled shafts using the osterberg test. Appl. Sci. 2020, 10, 6169. [CrossRef]

10. Doan, L.V.; Lehane, B.M. CPT-based design method for axial capacities of drilled shafts and auger cast-in-place piles. J. Geotech. Geoenvironmental Eng. 2021, 147, 04021077. [CrossRef]

11. Farhangi, V.; Karakouzian, M.; Geertsema, M. Effect of micropiles on clean sand liquefaction risk based on CPT and SPT. Appl. Sci. 2020, 10, 3111. [CrossRef]

12. Qubain, B.S.; Seksinsky, E.J.; Li, J.C.; Nuzha, K.; Eshete, D.W. Drilled shaft load testing during Design. In Proceedings of the International Foundations Congress and Equipment Expo, Dallas, TX, USA, 10-14 May 2021; Volume 323, pp. 257-266.

13. Baca, M.; Rybak, J. Pile base and shaft capacity under various types of loading. Appl. Sci. 2021, 11, 3396. [CrossRef]

14. Roling, M.J.; Sritharan, S.; Suleiman, T.M. Introduction to PILOT database and establishment of LRFD resistance factors for the construction control of driven steel H-piles. J. Bridge Eng. 2011, 16, 728-738. [CrossRef]

15. Abu-Hejleh, N.; DiMaggio, W.M.; Kramer, S. Implementation of AASHTO LRFD design specifications for driven piles. Fed. Highw. Adm. 2013. Rep. No FHWA RC-13-001.

16. Haque, M.N.; Abu-Farsakh, M. Estimation of pile setup and incorporation of resistance factor in load resistance factor design framework. J. Geotech. Geoenvironmental Eng. 2018, 144, 04018077. [CrossRef]

17. Foye, K.C.; Salgado, R.; Scott, B. Resistance factors for use in shallow foundation LRFD. J. Geotech. Geoenvironmental Eng. 2006, 132, 1208-1218. [CrossRef]

18. Komurka, V.E.; Winter, C.J.; Maxwell, S.G. Applying separate safety factors to end-of-drive and set-up components of driven pile capacity. In Proceeding of the 13th Great Lakes Geotechnical and Geoenvironmental Conference, Milwaukee, WI, USA, 13 May 2005; pp. 65-80.

19. Yang, L.; Liang, R. Incorporating set-up into reliability-based design of driven piles in clay. Can. Geotech. J. 2006, 43, 946-955. [CrossRef]

20. Kim, D.; Lee, J. Resistance factor contour plot analyses of load and resistance factor design of axially-loaded driven piles in clays. Comput. Geotech. 2012, 44, 9-19. [CrossRef]

21. Ng, K.; Sritharan, S. Integration of construction control and pile setup into load and resistance factor design of piles. Soils Found. 2014, 54, 197-208. [CrossRef]

22. Bian, X.Y.; Zheng, J.J.; Xu, Z.J.; Zhang, R.J. A method to calculate resistance factors for LRFD of driven piles. In Proceedings of the 6th Asian-Pacific Symposium on Structural Reliability and its Applications (APSSRA2016), Shanghai, China, 28-30 May 2016; pp. 157-163.

23. Bian, X.Y.; Xu, Z.J.; Zhang, R.J. Resistance factor calculations for LRFD of driven piles based on setup effects. Results Phys. 2018, 11, 489-494. [CrossRef]

24. Skov, R.; Denver, H. Time dependence of bearing capacity of piles. In Proceedings of the 3rd International Conference on the Application of Stress-Wave Theory to Piles, Ottawa, ON, Canada, 25-27 May 1988; pp. 879-888.

25. Long, J.H.; Kerrigan, J.A.; Wysochey, M.H. Measured time effects for axial capacity of driven piling. Transp. Res. Rec. 1999, 1663, 8-15. [CrossRef]

26. Svinkin, M.R.; Morgano, C.M.; Morvant, M. Pile capacity as a function of time in clayey and sandy soils. In Proceedings of the 5th International Conference and Exhibition on Piling and Deep Foundations, Bruges, Belgium, 13-15 June 1994; pp. 1.11.1-1.11.8.

27. Bogard, J.D.; Matlock, H. Application of model pile tests to axial pile design. Am. Soc. Civ. Eng. 1990, 3, $217-278$.

28. AASHTO. LRFD Bridge Design Specifications, 4th ed.; American Association of State Highway and Transportation Officials: Washington, DC, USA, 2007.

29. Yang, L.; Liang, R. Incorporating setup into load and resistance factor design of driven piles in sand. Can. Geotech. J. 2009, 46, 296-305. [CrossRef] 
30. Paikowsky, S.G.; Birgisson, B.; McVay, M.; Nguyen, T.; Kuo, C.; Beacher, G.; Ayyub, B.; Stenersen, K.; O’Malley, K.; Chernauskas, L. Load and resistance factor design (LRFD) for deep foundations. In Proceeding of the 6th International Conference on the Application of Stress-Wave Theory to Piles, Sao Paulo, Brazil, 28-29 September 2004; pp. 281-304.

31. Hansell, W.C.; Viest, I.M. Load factor design for steel highway bridges. AISC Eng. J. Am. Inst. Steel Constr. 1971, 8, 113-123.

32. Perez, A.; Birgisson, B.; Zhang, L.; McVay, M.C.; Putcha, S. Load and resistance factor design (LRFD) for driven piles using dynamic methods-a florida perspective. Geotech. Test. J. 2000, 23, 55-66.

33. Zhang, L.M.; Li, D.Q.; Tang, W.H. Reliability of bored pile foundations considering bias in failure criteria. Can. Geotech. J. 2005, 42, 1086-1093. [CrossRef]

34. Barker, R.; Duncan, J.; Rojiani, K. Manuals for the Design of Bridge Foundations; National Cooperative Highway Research Program (NCHRP) Report 343; Transportation Research Board: Washington, DC, USA, 1991.

35. Zhang, L.M.; Tang, W.H. Bias in axial capacity of single bored piles arising from failure criteria. In Proceedings of the International Conference on Structural Safety and Reliability, Newport Beach, CA, USA, 17-22 June 2001; pp. 1-8. 